DOI: http://doi.org/10.21698/simi.2018.fp22

\title{
APPROACHES TO PREDICT THE IMPACT OF AIR ATMOSPHERIC COMPONENT IN ENVIRONMENTAL IMPACT ASSESSMENT REPORTS IN ASSESSING EXTENSIONS TO ACTIVE INDUSTRIAL OBJECTS
}

Antoaneta Stefanova, Margarita Filipova

Ruse University, 7017, 8 Studentska, Ruse, astefanova@uni-ruse.bg, mphilipova@uni-ruse.bg, Bulgaria

\begin{abstract}
The article deals with the approaches for predicting the impact on the Atmospheric Air component in the approved reports (Environmental Impact Assessment Reports EIAR) for the expansion of active industrial sites on the territory of the Republic of Bulgaria for the period 2013-2016. Different approaches used by independent environment experts have been identified as incoming forecasting data - using approved Inventory Methodologies, established emission limit values for the respective production under regulatory acts etc.

The purpose of the study is to compare the different approaches for predicting the impacts on the component Ambient air for a particular site and to draw a conclusion on the approach with the least variance. The need for a single methodology for assessing the Atmospheric Air component in the EIAR is reflecting the planned investment - an extension of an existing site. This need is studied and commented in the paper.
\end{abstract}

Keywords: atmospheric air, environmental impact assessment, forecasting, pollutants

\section{Introduction}

The main objective of the present paper is to study the applied methods for assessing the impact on the atmospheric air for the extensions and reconstructions of existing sites subject to a mandatory procedure for assessment of their impact on the environment.

The research objectives are:

Studying of the sites subject to expansion documentation of completed Environmental Impact Assessment (EIA) procedures on the territory of the regions Razgrad, Ruse and Silistra, Republic of Bulgaria for the period 2013 - 2016.

Establishing the methodology used to assess the impact on the Atmospheric Air component in the approved EIAR for the identified sites for the same period 20132016.

Studying of possible deviations in the conclusions of impact on the Atmospheric Air component using different methodologies for a selected specific site. 


\section{INTERNATIONAL SYMPOSIUM "THE ENVIRONMENT AND THE INDUSTRY", SIMI 2018, PROCEEDINGS BOOK}

In order to provide sufficient information on the methodologies used, the EIAR of the sites subject to the extension of the activity have examined all the agreed reporting tasks and the environmental impact assessment reports themselves for the period 2013-2016 concerning sites subject to expansion of the activity, which will be realized on the territory of the three regions of the Republic of Bulgaria.

\section{Materials and Methods}

The necessary information for the analysis is providing through:

Use of publicly available information from the official site of the competent Bulgarian regional authority for the approval of environmental assessment reports for the three areas - Ruse, Razgrad and Silistra - Regional Inspectorate for Environment and Water - Ruse (EIAR 2014, EIAR 2015b, EIA 2015, EIA 2016).

Use of publicly available information from the official website of the Bulgarian Ministry of Environment and Water (EIAR 2013b, EIAR 2015a, EIAR 2017).

Information provided by the Regional Inspectorate of Environment and Water Ruse under the Access to Public Information Act - for the procedures with missing data in the public registers (EIAR 2013a).

\section{Results and Discussion}

Investigation of the documentation of completed EIA procedures on the territory of Ruse, Razgrad and Silistra Districts for the period 2013-2016 for sites subject to expansion. From the survey of all approved sites for the period 2013-2016, which will be realized on the territory of the Bulgarian districts of Ruse, Razgrad and Silistra we have choosen the following sites subject to extensions.

Intensive breeding of poultry or pigs. Objects for intensive rearing of poultry - 4 sites (EIAR 2013a, EIAR 2013b, EIAR 2014, EIA 2016) and 2 sites for intensive rearing of pigs (EIAR 2015b, EIA 2015).

Non-ferrous alloying / alloying of non-ferrous metals and surface treatment of metals - 1 object (EIAR 2017).

Manufacture of gutron and bitumen - 1 site (EIAR 2015a).

Six of this sites are regulated by the Sixth Chapter of the Law for the Protection of the Environment, which means that $75 \%$ (or 6 sites) are active in intensive breeding of poultry and pigs. A major part of approved sites in the three areas under consideration is in the frame of the Intensive Livestock Sector.

Establishing the methodologies used to assess the impact on the Atmospheric Air component in approved environmental impact assessment reports from the period under review for the identified sites. The in-depth study of the approaches for assessment of the impact on the Atmospheric Air component in the EIAR shows that we can group the applied methodologies into three main groups:

Group no. 1. Use of validated inventory methodologies for the pollutants expected to be emitted from the objects in the ambient air. This group also includes inventories with emission factors, corrected by taking into account the applied pollutant reduction measures in the specific site; 


\section{INTERNATIONAL SYMPOSIUM "THE ENVIRONMENT AND THE INDUSTRY", SIMI 2018, PROCEEDINGS BOOK}

Group no. 2. Use of established emission limit values in ambient air according to normative documents. A study conducted in the Environmental Impact Assessment Guidelines also found the availability of a third group of methods, namely

Group no. 3. Actual measurements of emissions from the existing part of the sites subject to expansion carried out by accredited laboratories.

In tabular form - Table 1- data are presented on the methods used to estimate the emissions of air in the areas subject to the expansion of the activity.

Table 1. Data on the methodologies used to estimate the emissions in the atmospheric air from the sites to be expanded

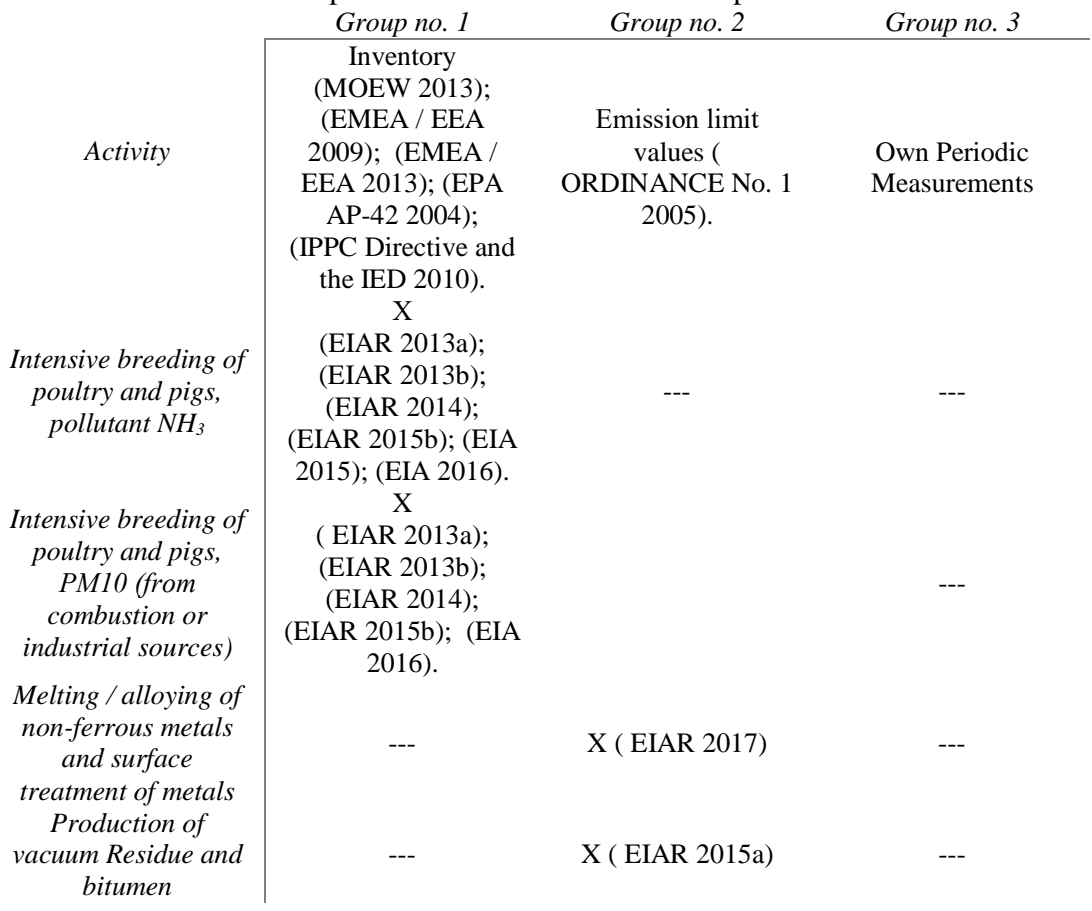

The data presented shows different methods to provide inbound data for planned extensions of objects to assess the impact on the Atmospheric Air component.

The practice in Environmental Impact Assessment procedures has imposed emission factors from established inventory methodologies for sites in the Intensive Livestock Sector (poultry and pigs) (MOEW 2013, EMEA / EEA 2009, EMEA / EEA 2013, EPA, AP-42 2004, IPPC Directive and the IED 2010).

The reason for the imposed practice is the specificity of the ventilation systems of the production halls (the displaced discharge of pollutants) and the lack of legal 


\section{INTERNATIONAL SYMPOSIUM "THE ENVIRONMENT AND THE INDUSTRY", SIMI 2018, PROCEEDINGS BOOK}

provision for conducting own periodic measurements. These types of objects are not of interest for this study.

Study of possible deviations in the application of the identified methodologies for a selected specific site. The study is carried out in the sequence presented on the block diagram of Figure 1.

For the purpose of the survey, an object of the Non-Ferrous Metals / Alloying Sector has been selected for which we have:

Data from own periodic measurements reported with annual environmental reports (Environmental Protection Act) and design data (Group no. 3);

Statutory Emission Limits on its Activities - (Group no. 2);

Emission factors according to inventory methodology (MOEW 2013) (Group no. 1). The selected site performs casting of non-ferrous metals, falling under item 2.5 of Annex 4 of the EPA (Environmental Protection Act), in which three melting furnaces with one discharge device (Table 1) are available. It is planned to install new furnaces to the plant, resulting in two new discharge devices (Table 1). The pollutant studied is a powder with a particle size of $5 \div 10 \mu \mathrm{m}$.

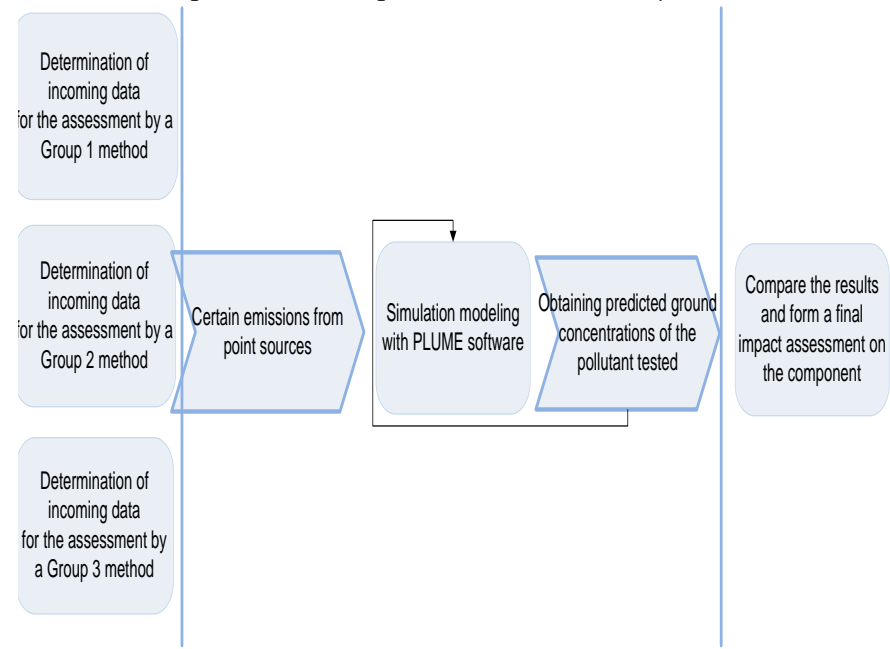

Figure 1. Block diagram of the study process

Task 1: Identify incoming data

Group no. 1. Up-to-date Unified Methodology for the Inventory of Air Pollutant Emissions (MOEW 2013) SNAP CODE 030310, was used to determine inputs for the assessment. Production of Aluminium from Secondary Raw Materials. The values obtained in ton / year for the pollutant are recalculated in grams per second under the 3 shift mode of the plant, 360 days / year. 


\section{INTERNATIONAL SYMPOSIUM "THE ENVIRONMENT AND THE INDUSTRY", SIMI 2018, PROCEEDINGS BOOK}

Group no. 2. To determine the input data for the assessment, the normative emission limit values for this type of activity are used (Ordinance no. 12005 ).

Group no. 3. To determine the input data for the assessment, averaged data from its own periodic measurements for the 2014-2016 period for the existing exhaust system and for the new chimneys data from the investment projects (Annual reports No 480) were used.

The results obtained are presented in tabular form - Table 2.

Table 2. Determination of incoming evaluation data

\begin{tabular}{l|ccc}
\multicolumn{1}{c}{ Source } & Group no. 1 & Group no. 2 & Group no. 3 \\
\cline { 2 - 4 } & & E dust, [g/s] & \\
Emitter 1 & 0.102 & 0.061 & 0.014 \\
Emitter 3 & 0.163 & 0.053 & 0.026 \\
Emitter 4 & 0.326 & 0.097 & 0.049 \\
Emitter 1 & 0.102 & 0.061 & 0.014
\end{tabular}

*E dust - dust emissions from a emitter

Task 2: Simulation modeling with PLUME software

With the help of the established software program at national level (Methodology for. 1998) a computer simulation was conducted to determine the mean annual concentration of dust before and after the installation expansion. The coordinate network $(\mathrm{x}, \mathrm{y})$ is being worked out, with the survey area of the air pool measuring 4000 x 4000 meters or 20 steps * 200 meters. The model is designed with a type of sub-surface area 'extra-urban area'. The site is located outside the regulation boundaries of the settlement.

An annual wind rose for the closest meteorological station - Razgrad (Climate Guide 1982), is used as an incoming data regarding the weather conditions. The spread of dust from the site before and after the expansion is presented in figures 2 to 7 .

The figures obtained through mathematical modeling represent the predicted value of the maximum annual average concentration for the pollutant and the distance from the last source that is expected to spread it. Isolations of lower ground concentrations from the determined maximum are plotted and their distribution in the created coordinate network.

Task 3: Comparison of the results and formation of a final impact assessment on the Atmospheric Air component

Table 2 presents the results of the average annual concentrations of pollutant dust obtained by applying a method of the three groups. An estimate of the impact on the Atmospheric Air Component was also calculated.

The estimated force of impact (EFI):

$$
E F I=\frac{C_{A A C}}{P H H_{A A}} \%
$$

where

$\mathrm{C}_{\mathrm{AAC}}$ are the calculated ground concentrations of the pollutant, $\mu \mathrm{g} / \mathrm{m}^{3}$ 


\section{INTERNATIONAL SYMPOSIUM "THE ENVIRONMENT AND THE INDUSTRY", SIMI 2018, PROCEEDINGS BOOK}

$\mathrm{PHH}_{\mathrm{AA}}$ is the annual average for the protection of human health $-40 \mu \mathrm{g} / \mathrm{m}^{3}$.

Table 3. Values of maximum average annual ground dust concentrations calculated using different methods

\begin{tabular}{|c|c|c|c|c|c|c|}
\hline \multirow{3}{*}{$\begin{array}{l}\text { Current } \\
\text { state } \\
\text { (before the } \\
\text { expansion) }\end{array}$} & \multicolumn{2}{|c|}{ Group no. 1} & \multicolumn{2}{|c|}{ Group no. 2} & \multicolumn{2}{|c|}{ Group no. 3} \\
\hline & $\begin{array}{l}\mathrm{AAC} \\
\mathrm{mg} / \mathrm{m}^{3}\end{array}$ & $\begin{array}{c}\text { Distance } \\
\mathrm{m}\end{array}$ & $\begin{array}{l}\mathrm{AAC} \\
\mathrm{mg} / \mathrm{m}^{3}\end{array}$ & $\begin{array}{c}\text { Distance } \\
\mathrm{m}\end{array}$ & $\begin{array}{l}\mathrm{AAC} \\
\mathrm{mg} / \mathrm{m}^{3}\end{array}$ & $\begin{array}{c}\text { Distance } \\
\mathrm{m}\end{array}$ \\
\hline & 0.00051 & 848.53 & 0.0003 & 848.53 & 0.00007 & 1131.37 \\
\hline $\begin{array}{l}\text { Forecast } \\
\text { (after the } \\
\text { expansion) }\end{array}$ & 0.00233 & 930.17 & 0.00086 & 930.17 & 0.00035 & 930.17 \\
\hline $\begin{array}{c}\text { EFI before } \\
\text { the } \\
\text { expansion, } \\
\%\end{array}$ & $1.27 \%$ & --- & $0.75 \%$ & --- & $0.17 \%$ & --- \\
\hline $\begin{array}{c}\text { EFI after } \\
\text { the } \\
\text { expansion, } \\
\%\end{array}$ & $5.8 \%$ & --- & $2.15 \%$ & --- & $0.87 \%$ & --- \\
\hline Impact & \multirow{3}{*}{\multicolumn{2}{|c|}{$\begin{array}{c}\text { Insignificant impact, } \\
\text { characterized by non- } \\
\text { essential sensitivity } \\
\left(<20 \% \text { of } \mathrm{PHH}_{\mathrm{AA}}\right) \text { and } \\
\text { low impact power } 5 \div 15 \\
\%\end{array}$}} & & & & \\
\hline $\begin{array}{l}\text { assessment } \\
\text { after the } \\
\text { expansion }\end{array}$ & & & \multirow{2}{*}{\multicolumn{2}{|c|}{$\begin{array}{l}\text { Insignificant impact, } \\
\text { characterized by non- } \\
\text { essential sensitivity } \\
\left(<20 \% \text { of } \mathrm{PHH}_{\mathrm{AA}}\right) \text { and } \\
\text { non-essential impact } \\
\text { power }<5 \%\end{array}$}} & \multirow{2}{*}{\multicolumn{2}{|c|}{$\begin{array}{l}\text { Insignificant impact, } \\
\text { characterized by non- } \\
\text { essential sensitivity } \\
\left(<20 \% \text { of } \mathrm{PHH}_{\mathrm{AA}}\right) \text { and } \\
\text { non-essential impact } \\
\text { power }<5 \%\end{array}$}} \\
\hline $\begin{array}{c}\text { Current } \\
\text { state } \\
\text { (before the } \\
\text { expansion) }\end{array}$ & & & & & & \\
\hline
\end{tabular}

*AAC - average annual concentration of dust

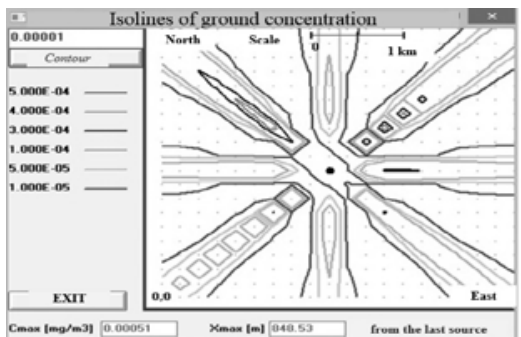

Figure 2. Isoliness of the average annual concentrations of the plant dust before its expansion using input data from Group 1 method

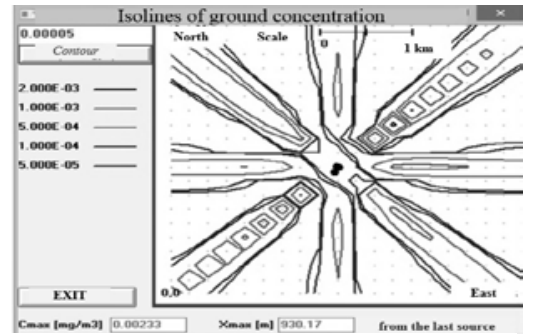

Figure 3. Isoliness of the average annual concentrations of the plant dust after its expansion using input data from Group 1 method 


\section{INTERNATIONAL SYMPOSIUM "THE ENVIRONMENT AND THE INDUSTRY", SIMI 2018, PROCEEDINGS BOOK}

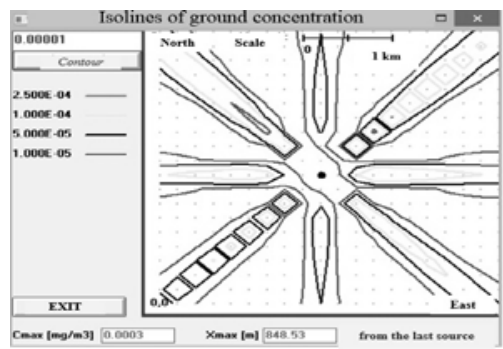

Figure 4. Isolines of the average annual concentrations of the plant dust before its expansion using input data from Group 2 method

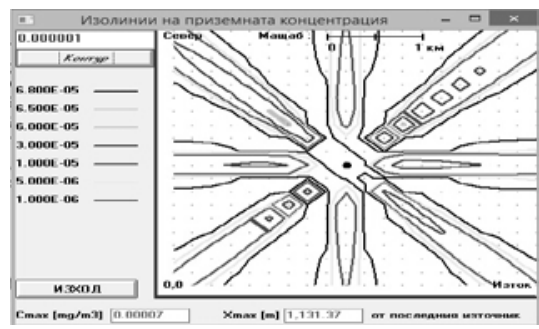

Figure 6. Isolines of the average annual concentrations of the plant dust before its expansion using input data from Group 3 method

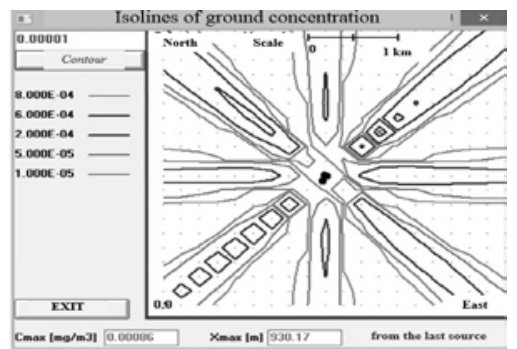

Figure 5. Isolines of the average annual concentrations of the plant dust after its expansion using input data from Group 2 method

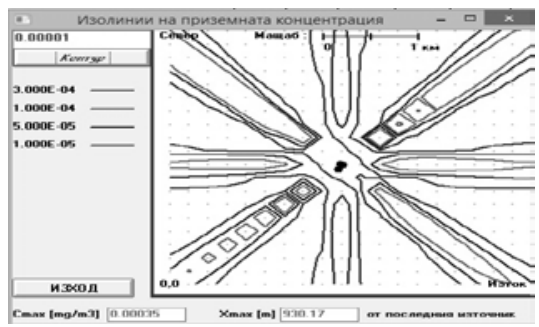

Figure 7. Isolines of the average annual concentrations of the plant dust after its expansion using input data from Group 3 method

\section{Conclusions}

The survey is about the production of site subject of expansion, with the following restrictions being imposed:

The site is considered without a cumulative assessment of the component as a result of the operation of existing industrial activities in the area;

Verification of predicted maximum single concentrations of the pollutant has not been performed;

Only one pollutant - a powder considered as PM10 - has been investigated.

Despite the above limitations for the particular site, we can draw the following conclusions:

It is not important which method for obtaining of incoming data is used. When applying the three scenarios described above, the result is the same - the impact assessment after the site expansion is of negligible impact. However, using the inventory method, a low impact is reported, unlike the other two applied methods, where the impact strength is considered insignificant. This necessitates the extension of the study with the formation of sufficiently concrete conclusions. 


\section{INTERNATIONAL SYMPOSIUM "THE ENVIRONMENT AND THE INDUSTRY", SIMI 2018, PROCEEDINGS BOOK}

There is a need for an in-depth study of the approved environmental impact assessment reports at national level, covering more pollutants, as well as estimating cumulative impacts in the application of methods by the three groups examined.

On the basis of the detailed study, the use of the most relevant methodology for the relevant sector should be prioritized to provide input data when assessing impact on the Atmospheric Air component.

\section{Acknowledgements}

The authors express their thanks to the employees of RIEW-Ruse for providing comprehensive information on the procedures under Chapter Six of the Environmental Protection Act.

\section{References}

Annual reports on the implementation of the activities covered by CoR No 480 2014/2014, 2015 and 2016. Available from: http://eea.government.bg/bg/r-r/rkpkz/godishni-dokladi-14/index. [01 August 2018].

AP-42, EPA Compilation of Air Pollutant Emission Factors - U.S.Environmental Protection Agency. Available from: https://www3.epa.gov/ttnchie1/ap42. [01 August 2018].

Best Available Techniques Reference Document (BREFs) developed under the IPPC Directive and the IED. Available from: http://eippcb.jrc.ec.europa.eu/reference. [01 August 2018].

Climate Guide for Bulgaria, vol. IV, Institute of Hydrology and Meteorology, Sofia 1982 .

EIAR for the site 'Farm for Intensive Growing of 102,850 Broilers with Sites Location III, Reg. IV, Reg. V, Reg. X and Reg. XI, District 180 of the Plan of the Town of Vetovo, Ruse District' RU 1-1 / 2013a of the Director of RIEWRuse.

EIAR for the project 'Increasing the capacity of a plant for intensive breeding of birds (growing broilers for broilers and broilers for broilers) from 625174 to 1 058010 places for birds with location properties with numbers 000175 and 000227 in the land of the village of Chervena voda, Ruse', which was concluded with Decision No. Py 3-4 / 2013b of the Director of RIEW-Ruse.

EIAR for the site 'Repair, expansion and equipment of a plant for intensive broiler breeding and reaching a total capacity of 314570 places for birds with location: property number 050036 in the land of Shumentsi village, Tutrakan', which was concluded with Decision No. Py 2-2 / 2014 of the Director of RIEW - Ruse.

EIAR for site 'Increase of the capacity of an existing gudron and bitumen plant from $10000 \mathrm{t} /$ year to $200000 \mathrm{t} /$ year by raw material, located in UPI XX and UPV XXVI on the plan of TM Ruse and construction of a new hydrocracking complex within the territory of UPI XXII on the plan of TM AD - Ruse for the production of petrol and diesel fuel from heavy oil fractions with a capacity of 250000 tons / year on raw material', concluded with Decision No. Py 2-2 / 2015a of the Director of RIEW-Ruse for partial approval of the investment. 


\section{INTERNATIONAL SYMPOSIUM "THE ENVIRONMENT AND THE INDUSTRY", SIMI 2018, PROCEEDINGS BOOK}

EIAR for site 'Combining two existing holdings in one, reconstruction of existing and building of new buildings in order to increase the capacity of the holding pig farm with location: the land of the village of Popina, Silistra municipality', concluded with Decision No RU 3-3 / 2015b of the Director of RIEW-Ruse.

EIA report for the site 'Reunification of five existing holdings / pigs / in one and increase of the capacity of the farm with location properties 056001, 053002, 053003, 053004, 053005, 053006, 053007 in the village of Vetren, Silistra municipality', which was concluded with Decision No Py-5-7 / 2015 of the Director of RIEW-Ruse.

EIA report for the site: 'Increase the capacity of an existing poultry house, repair, reconstruction and commissioning of two existing poultry buildings in order to reach the total capacity of the poultry farm 122724 birds, property № 000058 in the land of village of Kichenitsa, Razgrad‘, which ended with Decision No PY-1-1 / 2016 of the Director of RIEW-Rousse.

EIAR for the site 'Installation of two aluminum recycling plants, aluminum chips and other waste containing aluminum for the production of standard aluminum alloys in ingots in a property with identifier 61710.506 .30 according to the plan of Razgrad, Razgrad municipality“, Which ended with Decision No PY1-2 / 2017 of the Director of RIEW-Ruse.

EMEA / EEA air pollutant emission inventory guidebook, 2009. Available from: http://www.eea.europa.eu/publications/emep-eea-emission-inventoryguidebook-2009. [01 August 2018].

EMEA / EEA EEA Air Pollutant Emission Guidelines Guide, 2013. Available from: http://www.eea.europa.eu/publications/emep-eea-guidebook-2013. [01 August 2018].

Environmental Protection Act Available from: http://www.lex.bg/bg/laws/ldoc/2135458102. [01 August 2018].

Methodology for calculation of leak height, dispersion and expected concentrations of pollutants in the ground layer of 25 February 1998 adopted by the Ministry of Environment and Waters, the Ministry of Regional Development and Public Works and the Ministry of Health. Available from: http://www5.moew.government.bg/. [01 August 2018].

Ordinance no. 1 of 27.06.2005 on emission limit values of pollutants emitted into the atmosphere from sites and activities with fixed emission sources. Available from: http://www5.moew.government.bg/?page_id=24089. [01 August 2018].

Updated unified methodology for inventory of emissions of harmful substances in air (Order No РД-165 / 20.02.2013 of MOEW). Available from: http://eea.government.bg/bg/legislation/air/methodology. [01 August 2018]. 